\title{
Mapping the northern portion of the Chelungpu fault, Taiwan by shallow reflection seismics
}

\author{
Chien-Ying Wang, Chien-Li Li, and Horng-Yuan Yen \\ Institute of Geophysics, National Central University, Chung-Li, Taiwan \\ Received 1 December 2001; revised 18 March 2002; accepted 9 April 2002; published 24 August 2002.
}

[1] The Chelungpu fault was activated by the 1999 Chi-Chi earthquake $(\mathrm{Mw}=7.6)$, Taiwan. This fault exhibited extraordinarily large surface ruptures (up to $9.8 \mathrm{~m}$ ) as well as underground fault slippages (up to $12 \mathrm{~m}$ ) during the earthquake. These large displacements were concentrated along the northern portion of the fault, $40 \mathrm{~km}$ north of the epicenter. To prepare data for the future drilling of deep wells in this area, many shallow seismic reflection surveys were conducted to investigate the sites. An approximate 3D structure of the fault surface can be deduced by this cost-effective approach. Although the depth penetration may be limited (e.g., 3 $\mathrm{km}$ ), the method still provides reliable information to study large ruptures, and to better plan future deep wells. INDEX TERMS: 0935 Exploration Geophysics: Seismic methods (3025); 8107 Tectonophysics: Continental neotectonics; 8110 Tectonophysics: Continental tectonics-general (0905); 8123 Tectonophysics: Dynamics, seismotectonics

\section{Introduction}

[2] The most significant feature of Taiwan's Bouguer gravity anomaly map is an overall gravity low ( $-61 \mathrm{mgal})$ near the center of the island (Figure 1). It covers an area of $80 \mathrm{~km} \times 80 \mathrm{~km}$, contoured by -50 mgal curves, which includes the Taichung basin, the Puli basin, and the foothills between them [Yen et al., 1998]. This area happens to be the region where the 1999 Chi-Chi earthquake $(\mathrm{Mw}=7.6)$ and its aftershocks were distributed [Shin and Teng, 2001]. Two apparently conflicting theories have been proposed to explain this gravity low. One is Wu et al. [1997] lithosphere collision model, which attributes this gravity low to a thick crust $(50 \mathrm{~km}$ ?) under the Central Mountain Range and the western foothills due to the collision of the Coastal Mountain Range from the east [Angelier, 1986]. Another theory is Suppe [1985] thin-skinned thrust model, which allows the structures above a decollement $(8-10 \mathrm{~km}$ deep) to be thrust into imbricated forms. The low density material is thought to be moved to deep places, which makes the gravity low. A detailed mapping of the structure beneath this anomalous gravity low area is necessary to ascertain which of these two models is more accurate.

[3] The 1999 Chi-Chi earthquake provided certain evidence in favor of the thin-skinned thrust model around the fault area [Wang et al., 2000], however, the crustal thickening is also possible in its eastern mountain side as shown by some deep aftershocks there [Lallemand, 2000; Kao and Chen, 2001]. In the thin-skinned model, the $8 \mathrm{~km}$ deep earthquake [Chang et al., 2000] triggered the existing Chelungpu fault, causing it to slide along a weak, shallowly dipping $\left(30^{\circ}\right)$ shale layer (Chinshui shale) until breaking the surface (Figure 1b). The most astonishing behavior of the Chelungpu fault is that the largest displacements both on the surface (up to $9.8 \mathrm{~m}$ horizontally, $5.6 \mathrm{~m}$ vertically) and underground (up to $12 \mathrm{~m}$ ), was not at the source area, but concentrated in its northern portion, $40 \mathrm{~km}$ north of the epicenter [Ma et al., 2000;
Lee et al., 2002]. The course of this $90 \mathrm{~km}$ fault trace also turns from a south-north to a northeast direction in this region, i.e., the Fengyuan-Shihkang area (Figure 1). There must be some unusual structures or lithologic variations beneath the Shihkang area to cause these strange rupture behaviors.

[4] In this study, we concentrated on the structures in the northern portion of the fault. Recently (2001/2), two shallow test wells were drilled close to the fault, one at the north near Fengyuan (450 m deep) and the other at the south near Nantou (220 m) (Figure 1). They revealed that much more complicated lithologic fearures in the northern well than in the southern well. A very high water content (over $45 \%$ ) was found within the fracture zone in the northern well [Tanaka et al., 2002]. These make it quite natural to choose the northern portion of the fault as a candidate site for possible deep well drilling. The Chelungpu fault deep drilling project has been cataloged by the International Continental Drilling Program (ICDP) [Ando et al., 2001]. In this paper, we will present the results of shallow seismic reflection surveys undertaken in this area, which may provide necessary information for the selection of future deep well sites $(2-5 \mathrm{~km}$ deep) and for the identification of factors that controll large slippages.

\section{Geologic Setting}

[5] The geology near the Chelungpu fault (Figure 1) is relatively simple [Chang, 1971; Chinese Petroleum Corporation, 1982]. The structural layers involved are (from top to bottom): the Toukoshan formation (gravels, Pleistocene), the Cholan formation (sand and shale, late Pliocene), the Chinshui formation (shale, early Pliocene), and Miocene deposits composed mainly of sand and shale, the topmost being the Kueichulin formation. The thrusting of the Chelungpu fault caused the Pliocene Chinshui and Cholan formations to move upward and become exposed on the eastern hanging-wall side, forming a hill. This thrust fault is estimated to have been shortened by a total of $13 \mathrm{~km}$ over the last two million years (Dr. Angelier, per. comm.). The western footwall side is covered with a $3 \mathrm{~km}$-thick Toukoshan gravel layer, which forms a basin of relatively flat structural layers. Figure $1 \mathrm{~b}$ gives a gross outlining of the underground structure of the area formed by compiling the oil-exploration types of seismic reflection studies and the proposed thin-skinned thrust model [Suppe, 1985]. It is obvious that the Chinshui shale is the key bed controlling the thrusting mechanism. This layer has a thickness of about $300 \mathrm{~m}$ composing mainly of shales and is probably over-pore pressured [Suppe and Wittke, 1977]. The Chelungpu fault slides along this bed as a bedding fault, as can be seen by examing the seismic sections in this paper. The smoothly curved shape of the Chinshui shale has apparently resulted from thrust faulting.

\section{Shallow Seismic Reflection Surveys}

[6] Over 20 shallow seismic reflection lines were deployed in the area to collect the basic underground information for the site investigation. Figure 2 depicts the location of each line as well as the overall topography of the area. The surface geology has been well mapped [CPC, 1982]. There are some high-level terraces on 
(a)

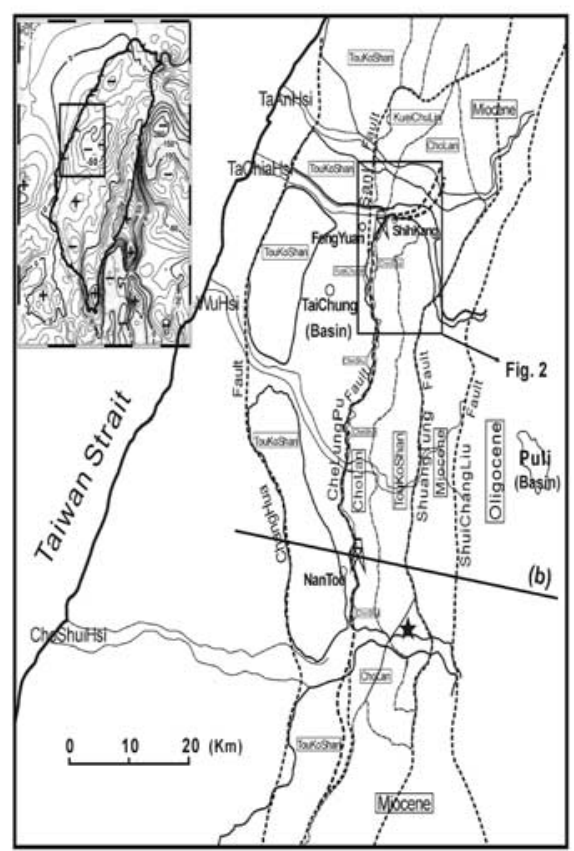

(b)

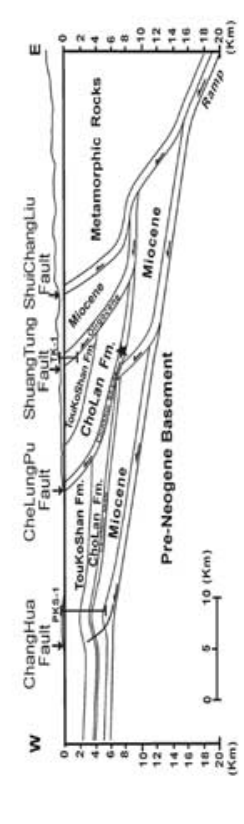

Figure 1. (a) A simplified geologic map of the area surrounding the Chelungpu fault. The inset shows the Taiwan Bouguer gravity anomaly map. Note the gravity low $(-61 \mathrm{mgal})$ in the study area. (b) A cross section sketch based on the thin-skinned thrust model. The imbricated structure of the western Taiwan foothills was formed due to thrusting along four sequential faults. The star denotes the Chi-Chi earthquake source.

the eastern and the northern sides, which imply an uplift of the structures beneath them. Although shallow reflection seismics has a survey size limitation (at most $1000 \mathrm{~m}$ long and $3000 \mathrm{~m}$ deep), it is much cheaper and easier to carry out in a rough topographic

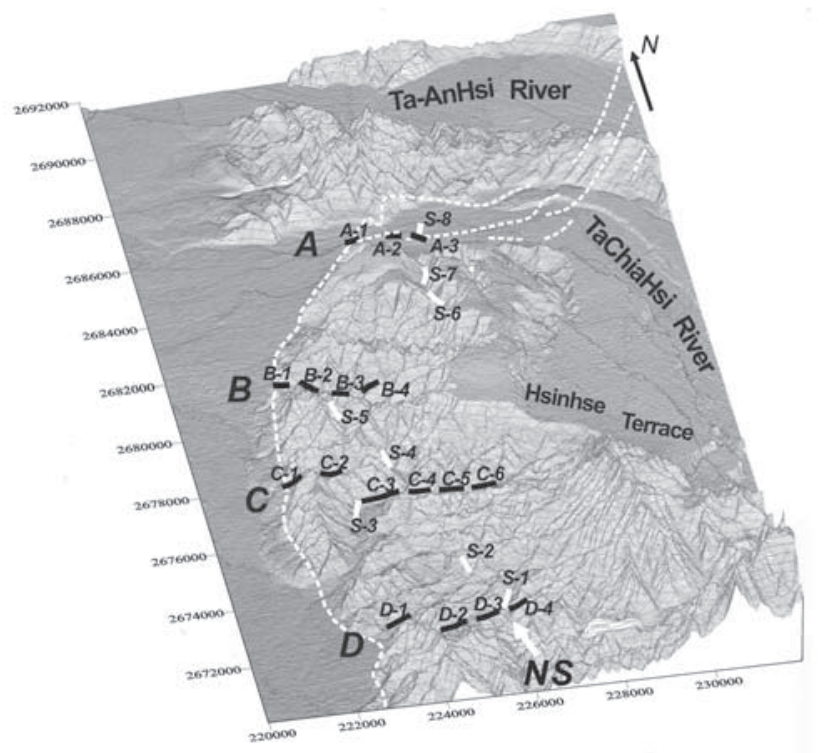

Figure 2. The topography of the northern portion of the Chelungpu fault. There are several terraces on the eastern and the northern sides, which imply an uplift of the structures beneath them. The dashed line describes the surface rupture of the Chelungpu fault. The five seismic reflection profiles are indicated.

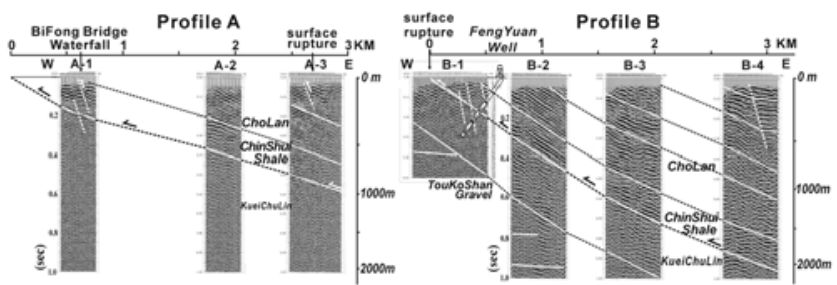

Figure 3. Seismic reflection sections along Profiles A and B. Profile A follows the southern bank of the Tachiahsi river, where large surface ruptures occurred (Shihkang). Profile B is a little south of Profile A. Section B-1 is just beside the recently drilled Fengyuan well (450 m deep). Note that the $220 \mathrm{~m}$ depth of the well can be connected to the surface fracture.

area. A long, oil-exploration type of seismic line is always difficult, perhaps even impossible in this kind of region, with its rugged surfaces, winding roads and short accessible distances. The shallow seismic method has the merits of mobility, efficiency, high-resolution and cost-effectiveness, which make it quite useful for mapping the structure in a hilly area like this case.

[7] The following survey equipments were used:

1. source: EWG-III impact pulse generator,

2. receiver: $\mathrm{OYO} 40 \mathrm{~Hz}$ geophone,

3. recorder: DAS-1 96 channel seismograph, and the survey parameters:

1. source interval: $6 \mathrm{~m}$,

2. receiver interval: $2 \mathrm{~m}$,

3. near-offset: $100 \mathrm{~m}$

4. fold: 16

5. sampling rate: $0.25 \mathrm{~ms}$,

6. low-cut filter: $40 \mathrm{~Hz}$.

[8] Most of the field work was carried out at night to avoid traffic noise. The data processing followed the standard procedures for CDP data, except for the emphasis of some dip filters and static corrections [Wang, 2002].

[9] A total of twenty-five seismic lines was acquired, which could be divided into 5 groups (profiles) as shown in Figures 3 to 5 . Figure 2 gives the location of each line. Each profile contains 3 to 8 sections, which are arranged in a series to form a long profile. The quality of the data is surprisingly good. The structures in the four EW profiles (Profiles A to D) are quite simple, full of eastward dipping layers with slightly varied dip angles between 18 to 35 degrees. By using the well-documented geologic map and the lithologic layers identified on the surface outcrops, we may assign the different lithologic layers to different parts of the sections. True amplitude seismic sections have also been prepared (not show) to assist this layer identification. Some detailed structural variation due to faulting may be observed in these delicate, highresolution seismic sections. For example, Profile B shows an apparent high-angle fracture on the upper part of its B-4 section, which may present a minor fault in a 'pop-up' structure proposed

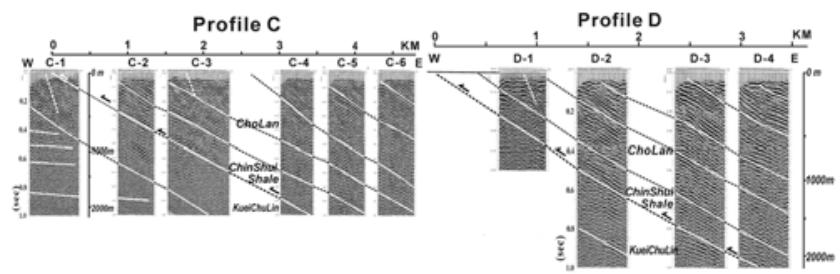

Figure 4. Seismic reflection sections along Profiles C and D. Profile C follows the Takunghsi river. Wide open spaces with low surface roughness have made this area a good candidate for deep well drilling. All the layers dip evenly to the east, which indicates a simple structure in this area. 


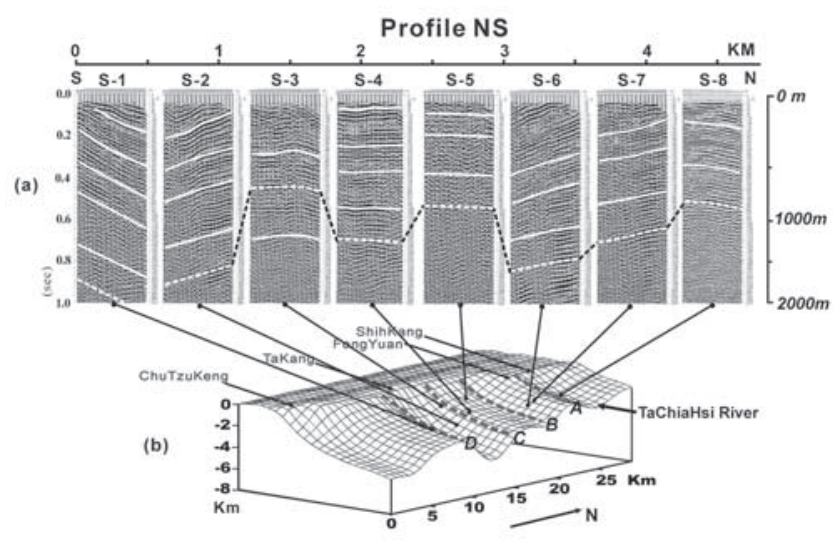

Figure 5. (a) A series of seismic reflection sections along a north-south profile (Profile NS). The dip angle of each section varies in an up-and-down manner, which leads to the conceptualization of a 3D undulating structure for the Chelungpu fault surface (the northern portion), as shown in (b).

for the terraces [Lee et al., 2002]. Profile C (Figure 4), which is a highly probable candidate site for a deep drill, shows that the target fault may be $0.5 \mathrm{~km}$ deep, $1 \mathrm{~km}$ distance from the surface fault trace, $1.2 \mathrm{~km}$ at $2 \mathrm{~km}$, and $2.5 \mathrm{~km}$ at $4 \mathrm{~km}$. These numbers may be used as reference for planning the deep drilling. We note that there is a Miocene Kueichulin formation under the Chelungpu fault (Chinshui shale), which has a thickness of about $800 \mathrm{~m}$ (Figure 4). An old fault (Sani fault, Figure 1a) is believed to be sited at the bottom of this layer and beneath it may be the younger Pleistocene Toukoshan gravel formation. Drilling to this gravel layer is highly recommended to determine any significant relationships between the old and the new faults.

[10] We also collected 8 short seismic lines (Profile NS) in the south-north direction, shown in Figure 5. Very interesting up and down undulations are found in this NS profile which parallel the fault or the structural strike direction. These dip variations and the ties between the EW and NS profiles allowed us to construct a 3D fault surface, which is described in Figure $5 \mathrm{~b}$. A very interesting swinging shape of the fault surface is found. The depressions on this surface are related to the westward flowing rivers in the area, which implies a close relationship of the geomorphology and the underground structure. This constructed 3D fault plane, besides dipping to the east, also shows a slight dip inclination to the south (about 10 degrees), which means that the fault surface becomes shallower as it moves from the south to the north, and is finally exposed at the surface along the banks of the Tachiahsi stream, i.e., the Shihkang area. It is also found that the Bouguer anomaly is characterized by a gradual decrease at a rate of $1 \mathrm{mgal} / \mathrm{km}$ southeastwardly [Chang, 1971]. This gradual decrease is obviously related to the $3 \mathrm{D}$ undulating structure for the fault surface. This structural variation can explain the abnormal rupturing orders found in the Fengyuan-Shihkang area. The fault surface may be very close to the surface here (as small as $200-500 \mathrm{~m}$ ), thus the ruptures broke the surface during the earthquake.

\section{Conclusions}

[11] The 1999 Chi-Chi earthquake presents a rare opportunity to directly probe into the fault zone where large slip has recently occurred. After several shallow test wells drilled beside the fault, a deep drilling project has been intensively planned [Ando et al., 2001]. This is an international project cataloged by the ICDP. Two deep wells at the range of $3-5 \mathrm{~km}$ are proposed to drill at the northern and the southern parts of the fault, respectively, due to their obviously distinct rupture behaviors. This paper provides some basic data to assist the decision of the drill site at the northern side where the shallow fault surface and the abnormal ruptures may have made it a good candidate site to drill.

[12] From the above description and discussion, we reach the following conclusions:

1. The structures along four EW shallow seismic profiles showed simple eastward dipping layers with slightly varied dip angles between 18 to 35 degrees. The structure in the target area is quite simple and thus is appropriate for successful drilling.

2. The profile along the Takunghsi river (Profile C), which is a candidate site for deep drilling, shows that the target fault may be $0.5 \mathrm{~km}$ deep $1 \mathrm{~km}$ distant from the surface fault trace, $1.2 \mathrm{~km}$ at $2 \mathrm{~km}$, and $2.5 \mathrm{~km}$ at $4 \mathrm{~km}$. However, a further drilling of $800 \mathrm{~m}$ to reach the deep hidden Toukoshan gravel layer is recommended.

3. An up and down undulating fault surface was found along the south-north profile (Profile NS). The constructed 3D fault plane however, shows a slight dipping to the south at an angle of about 10 degrees.

4. The inclined fault surface becomes shallower as it runs from the south to the north and is finally exposed at the banks of the Tachiahsi river. This leads to the abnormal displacements in this area during the earthquake.

[13] Acknowledgments. This research was supported by the National Science Council of Taiwan under grant NSC90-2119-M-008-005. Many graduate and undergraduate students supplied large amounts of labor during the field work, which is highly appreciated.

\section{References}

Ando, M., Y. B. Tsai, M. Zoback, K. Suyehiro, H. Ito, J. Mori, and H. Tanaka, Drilling the seismogenic zone of the Chelungpu Fault, Taiwan: Investigating physics of faulting for a recent large earthquake, ICDP Workshop on Drilling the Chelungpu Fault, Taipei, 2001

Angelier, J., Geodynamics of the Eurasia-Philippine Sea Plate boundary: Preface, Tectonophys., 125, 1-3, 1986.

Chinese Petroleum Corporation, The geologic maps of Taichung and Chiayi, Taiwan Petrol. Exploration Division Publ., Taiwan, 1982.

Chang, C. H., Y. M. Wu, T. C. Shin, and C. Y. Wang, Relocation of the 1999 Chi-Chi earthquake in Taiwan, TAO, 11, 581-590, 2000.

Chang, S. L., Subsurface geologic study of the Taichung Basin, Taiwan, Petro. Geol. Taiwan, 8, 21-45, 1971 .

Kao, H., and W. P. Chen, The Chi-Chi earthquake sequence: Active, out-ofsequence thrust faulting in Taiwan, Science, 30, 2346-2349, 2001.

Lallemand, S., Was the 1999 Chi-Chi earthquake in Taiwan a "subduction earthquake"?, TAO, 3, 709-720, 2000.

Lee, J. C., H. T. Chu, J. Angelier, Y. C. Chan, J. C. Hu, C. Y. Lu, and R. J. Rau, Geometry and structure of northern surface ruptures of the 1999 $\mathrm{Mw}=7.6 \mathrm{Chi}-\mathrm{Chi}$ Taiwan earthquake: Influence from inherited fold belt structures, J. Struc. Geol., 24, 173-192, 2002.

Ma, K. F., T. R. Song, S. J. Lee, and S. I. Wu, Spatial slip distribution of the December 20, 1999, Chi-Chi Taiwan earthquake inverted from teleseismic data, Geophys. Res, Lett., 27, 3417-3420, 2000.

Shin, T. C., and T. L. Teng, An overview of the 1999 Chi-Chi, Taiwan, earthquake, Bull. Seis. Soc. Am., 91, 895-913, 2001.

Suppe, J., Principles of Structural Geology, Prentice-Hall, Englewood Cliffs, 537 pp., 1985.

Suppe, J., and J. H. Wittke, Abnormal fluid pressure in relation to stratigrahy and structure in the active fold-and-thrust belt of northwestern Taiwan, Petro. Geol. Taiwan, 14, 11-24, 1977.

Tanaka, H., C. Y. Wang, W. M. Chen, A. Sakaguchi, K. Ujiie, H. Ito, and M. Ando, Initial science report of shallow drilling penetrating into Chelungpu fault zone, $T A O$, in review, 2002

Wang, C. Y., C. H. Chang, and H. Y. Yen, An interpretation of the 1999 Chi-Chi earthquake in Taiwan based on the thin-skinned thrust model, TAO, 11, 609-630, 2000.

Wang, C. Y., The detection of a recent earthquake fault by the shallow reflection seismic method, Geophys., to appear, 2002.

Wu, F. T., R. J. Rau, and D. Salzberg, Taiwan orogeny: Thin-skinned or lithospheric collision?, Tectonophys., 274, 191-220, 1997.

Yen, H. Y., Y. H. Yeh, and F. T. Wu, Two-dimensional crustal structures of Taiwan from gravity data, Tectonics, 17, 104-111, 1998.

C.-Y. Wang, C.-L. Li, and H.-Y. Yen, Institute of Geophysics, National Central Univ., Chung-Li 32054, Taiwan. (wangcy@cc.ncu.edu.tw; corwintrix@yahoo.com.tw; Yenhy@earth.sinica.edu.tw) 